\title{
On the temporary nature of disruption of fear-potentiated startle following PKM $\zeta$ inhibition in the amygdale
}

\author{
Karim Nader* \\ Department of Psychology, McGill University, Montreal, QC, Canada \\ *Correspondence: karim.nader@mcgill.ca
}

\section{A commentary on}

Temporary disruption of fear-potentiated startle following PKMzeta inhibition in the amygdala

by Parsons, R. G., and Davis, M. (2011). Nat. Neurosci. 14, 295-296.

In 2006, a molecule called PKM $\zeta$ was suggested to mediate memory maintenance (Pastalkova et al., 2006). In cellular models of long-term memory (LTM), such as long-term potentiation (LTP; Martin et al., 2000), inhibition of PKM $\zeta$ with the zeta inhibitory peptide (ZIP) reverses the maintenance of late-LTP, without affecting early-LTP, a cellular correlate of short term memory (STM; Serrano et al., 2005). In addition, ZIP was thought to affect AMPA receptor trafficking which is considered to be a critical component of LTM (Malinow and Malenka, 2002). The effect of ZIP on behavior has been found to be incredibly similar to its effects on cellular models of learning and memory; intact acquisition and STM but impaired LTM (amnesia; Sacktor, 2010) lasting up to 3 months in some cases (Serrano et al., 2008). Occasionally, animals will "recover" from their amnesia and behave as if they remember the original task. The vast majority of reported cases of such spontaneous recovery happens within 1-2 days after the induction of amnesia (Miller and Springer, 1974). Recently, we demonstrated that inhibition of endocytosis of AMPA receptors prevented ZIP induced changes in behavior, physiology and biochemistry (Migues et al., 2010). Currently, a cohesive story is emerging across levels of analyses concerning memory maintenance (Sacktor, 2010).

The one exception to the developing narrative is the study by Parsons and Davis (2011) which suggest "that PKM tion does not erase memory, but temporarily disrupts expression of memory." The authors used an olfactory fear potentiated startle reflex task coupled with ZIP infusions into the basolateral amygdala (BLA), and tested retention impairments under a variety of conditions. One of the factors that will affect the chance of recovery is how robust the amnesia is. When the performance impairment is small, the probability of recovery is high (Davis and Rosenzweig, 1978). The dose used by the authors was four times lower that used in 9 of 10 studies on the topic (Serrano et al., 2008; Migues et al., 2010). Therefore, in all likelihood less amnesia will be induced increasing the probability that amnesia will recover (Davis and Rosenzweig, 1978). It would be important to see if using the higher doses as used by majority of scientists in the field would lead to a long-term impairment in the paradigm used by Parson and Davis.

The authors report that 1 day after receiving ZIP infusions, animals show decreased levels of performance compared to animals receiving vehicle infusions suggesting that the animals were amnesic. However with a longer interval between injection and testing, the groups show the same levels of freezing (suggesting that the animals were no longer amnesic). In order to conclude that recovery from either extinction (Bouton, 1993) or amnesia (Kohlenberg and Trabasso, 1968; Miller and Springer, 1974) has occurred, it is crucial to demonstrate that performance has significantly increased or "recovered" over time. No such comparison was performed. Instead, $t$-tests between vehicle and ZIP groups at each time point are reported. The authors interpret significant statistical difference as evidence for amnesia and its absence as evidence for the lack of amnesia. This might be acceptable if the baseline responding of animals in the control group did not change as well. Unfortunately, reduced performance of vehicle groups are more striking than any putative increase in performance in ZIP groups. In some cases (their Figure 3B) the levels of responding for the vehicle group was reduced by $75 \%$ whereas the increase in responding by the ZIP group was approximately $20 \%$. If the scale of the right panel is adjusted to be the same as the left panel, then it is clear that the vast majority of observed changes in behavior are due to reduced performance of the control groups (forgetting), as opposed to increased performance by the ZIP treated groups.

A related issue is the apparent lack of statistical power specifically in experiments which have more than 10 day interval from ZIP infusions to testing. Taking their Figure S2 as an example, the authors claim the data indicate recovery from amnesia. However, the SE of their control group is so large that it is unclear if any impairment could be found significantly different statistically. Therefore, it would seem that the reported spontaneous recovery is due to forgetting in the controls groups, and a lack of statistical power in those experiments.

Theoretically, the paradigm used by the authors is called the recovery from amnesia The paradigm after 1973 was logically unable to resolve the nature of amnesia, leading to the current discord concerning the nature of amnesia (Gold and King, 1974; Miller and Springer, 1974; Nader and Wang, 2006). In short, it was demonstrated that recovery from amnesia could also be consistent with the erasure of the previous memory (Gold et al., 1973; Nader and Wang, 2006; Squire, 2006). Therefore, after 1973 recovery from amnesia was no longer considered to be categorical evidence in favor of a retrieval impairment being overcome as, it was also logically consistent with memory loss (Nader and Wang, 2006). According to this logic, the impairment induced by ZIP could be partial erasure of the memory. Any significant increases in performance might be mediated by incubation of that memory (increases in responding over time), new learning adding onto the residual memory (Nader and Wang, 2006; Squire, 2006). For this reason we have argued that a new task must be developed to test this important issue (Nader and Wang, 2006). 
In summary, the authors' conclusion that their results "do not support the suggestion that PKM $\zeta$ activity underlies permanent storage of fear memories in all parts of the brain" is first, not a novel one, as PKM $\zeta$ activity has already been demonstrated to be not critical for all forms of memory (Serrano et al., 2008), and second, is itself not warranted by their evidence. First, the appropriate statistical analysis to evaluate spontaneous recovery was never performed and there is no evidence to demonstrate that their paradigm has the statistical power to detect differences between the two groups of any kind when the first test is performed 10 days after infusions. Second, the most significant change in behavior is decreased performance of control groups due to forgetting over time. Third, a low dose of ZIP makes recovery more likely to occur (Davis and Rosenzweig, 1978). Lastly, the authors used a task that that cannot differentiate between storage and retrieval impairment views of recovery from amnesia (Gold et al., 1973; Nader and Wang, 2006).

\section{ACKNOWLEDGMENTS}

The author would like to thank A. Baker, E. Einarsson, T. Sacktor, V. Migues O. Hardt for their suggestions on this manuscript.

\section{REFERENCES}

Bouton, M. E. (1993). Context, time, and memory retrieval in the interference paradigms of Pavlovian learning. Psychol. Bull. 114, 80-99.

Davis, H. P., and Rosenzweig, M. R. (1978). Recovery as a function of the degree of amnesia due to protein synthesis inhibition. Pharmacol. Biochem. Behav. 8, 701-710.

Gold, P., and King, R. (1974). Storage failure versus retrieval failure. Psychol. Rev. 81, 465-469.

Gold, P. E., Haycock, J. W., Macri, J., and McGaugh, J. L. (1973). Retrograde amnesia and the "reminder effect": an alternative interpretation. Science 180, 1199-1201.

Kohlenberg, R., and Trabasso, T. O. M. (1968). Recovery of a conditioned emotional response after one or two electroconvulsive shocks. J. Comp. Physiol. Psychol. 65, 270-273.

Malinow, R., and Malenka, R. C. (2002). AMPA receptor trafficking and synaptic plasticity. Annu. Rev. Neurosci. 25, 103-126.

Martin, S. J., Grimwood, P. D., and Morris, R. G. (2000). Synaptic plasticity and memory: an evaluation of the hypothesis [In Process Citation]. Annu. Rev. Neurosci. 23, 649-711.

Migues, P. V., Hardt, O., Wu, D. C., Gamache, K., Sacktor, T. C., Wang, Y. T., and Nader, K. (2010). PKMzeta maintains memories by regulating GluR2-dependent AMPA receptor trafficking. Nat. Neurosci. 13, 630-634.

Miller, R., and Springer, A. (1974). Implications of recovery from experimental amnesia. Psychol. Rev. 81, 470-473.

Nader, K., and Wang, S. H. (2006). Fading in. Learn. Mem. 13, 530-535.

Parsons, R. G., and Davis, M. (2011). Temporary disruption of fear-potentiated startle following PKMzeta inhibition in the amygdala. Nat. Neurosci. 14 295-296.

Pastalkova, E., Serrano, P., Pinkhasova, D., Wallace, E., Fenton, A. A., and Sacktor, T. C. (2006). Storage of spatial information by the maintenance mechanism of LTP. Science 313, 1141-1144.

Sacktor, T. C. (2010). How does PKMzeta maintain longterm memory? Nat. Rev. Neurosci. 12, 9-15.

Serrano, P., Friedman, E. L., Kenney, J., Taubenfeld, S. M., Zimmerman, J. M., Hanna, J., Alberini, C., Kelley, A. E., Maren, S., Rudy, J. W., Yin, J. C., Sacktor, T. C., and Fenton,A.A. (2008). PKMzeta maintains spatial, instrumental, and classically conditioned long-term memories. PLoS Biol. 6, 2698-2706. doi: 10.1371/ journal.pbio.0060318

Serrano, P., Yao, Y., and Sacktor, T. C. (2005). Persistent phosphorylation by protein kinase Mzeta maintains late-phase long-term potentiation. J. Neurosci. 25, 1979-1984.

Squire, L. R. (2006). Lost forever or temporarily misplaced? The long debate about the nature of memory impairment. Learn. Mem. 13, 522-529.

Received: 07 May 2011; accepted: 26 May 2011; published online: 20 June 2011.

Citation: Nader K (2011) On the temporary nature of disruption of fear-potentiated startle following PKM inhibition in the amygdale (2011). Front. Behav. Neurosci. 5:29. doi: 10.3389/fnbeh.2011.00029

Copyright (c) 2011 Nader. This is an open-access article subject to a non-exclusive license between the authors and Frontiers Media SA, which permits use, distribution and reproduction in other forums, provided the original authors and source are credited and other Frontiers conditions are complied with. 